\title{
Perception of information about COVID-19 and protective behaviours in relation to feelings of anxiety and happiness
}

\author{
Aulia Iskandarsyah ${ }^{1,2}$, Whisnu Yudiana ${ }^{1,2}$, Arina Shabrina ${ }^{1}$, Jan Passchier ${ }^{3}$ \\ ${ }^{1}$ Department of Clinical Psychology, Faculty of Psychology, Universitas Padjadjaran, Bandung, Indonesia \\ ${ }^{2}$ Center for Psychological Innovation and Research, Faculty of Psychology, Universitas Padjadjaran, Bandung, Indonesia \\ ${ }^{3}$ Faculty of Behavioural and Movement Sciences, VU University Amsterdam, Amsterdam, Netherlands
}

\begin{tabular}{l} 
Article Info \\
\hline Article history: \\
Received 11 May, 2021 \\
Revised Oct 30, 2021 \\
Accepted Nov 10, 2021 \\
\hline
\end{tabular}

Keywords:

Anxiety

COVID-19

Happiness

Health behaviour

Information provision

Mental health

\begin{abstract}
This study aimed to assess the perception of the coronavirus disease 2019 (COVID-19) information provision and the health protective behavior as potential factors of feelings of anxiety and happiness among the general population in Indonesia during the outbreak. We conducted an online survey using snowball sampling techniques. The online survey collected information about demographic data, information provision of COVID-19, health prevention behaviors, and feelings of anxiety and happiness. This study involved 3,686 participants in Indonesia in the period from $2^{\text {nd }}$ of April to $4^{\text {th }}$ of April 2020. We found that the most frequent source of information reported was social media. The majority of participants were satisfied with the amount of information provided (98\%), however 54\% of the participants reported that no information or very little information about the screening/test and the treatment of COVID-19 was provided. The most frequent protective behaviour was implemented cough attitude, avoided handshake, and applied physical distancing. High exposure of Information about COVID-19 and doing preventive measures were associated with greater anxiety. Nonetheless, some preventive measures appeared to be positively associated with feelings of happiness. Our results give an indications about the information provision, application of preventive measure and the factors associated with feelings of anxiety and happiness.
\end{abstract}

This is an open access article under the CC BY-SA license.

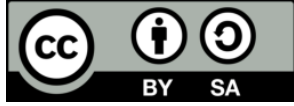

\section{Corresponding Author:}

Aulia Iskandarsyah

Department of Clinical Psychology, Faculty of Psychology, Universitas Padjadjaran

Jl. Raya Bandung Sumedang KM.21, Sumedang, West Java, Indonesia

Email: a.iskandarsyah@unpad.ac.id

\section{INTRODUCTION}

In December 2019, an outbreak of a novel coronavirus disease 2019 (COVID-19) was confirmed in Wuhan, China [1]. Considering the characteristic of the new coronavirus type (SARS-CoV-2) and the high potential for infection, the World Health Organization (WHO) affirmed the outbreak as a public health emergency on January 30, 2020 which became an international concern. WHO on March 11, 2020 declared COVID-19 as a pandemic. The first case of coronavirus disease in Indonesia was identified on 2nd of March 2020. According to the WHO data, on November 2021, there were 251,266,207 confirmed cases and 5,070,244 deaths reported in the world and in Indonesia there were 4,249,758 confirmed cases and 143,608 deaths related to COVID-19 [2].

Like many other countries, the Indonesian government has also taken many measures for the prevention and control of the pandemic. But, unlike other countries, enforceable measures in Indonesia are much less restrictive than the 'lockdowns' achieved in some European countries, New Zealand and areas in 
the United States. For example, New Zealand government implemented a strict lockdown which part of a 'go early, go hard' COVID-19 elimination strategy. On of March 3, 2020 the day after the first case was confirmed, the Indonesian government enforced a large-scale social restriction for two weeks or longer if needed. Social restriction restrained most non-essential activity outside the home, with all schools and nonessential businesses being closed. Workers were ordered to work from home and students continued their study at home. The government endorsed a health protocol for public to follow. Indonesian public health measures resembled Japan's 'mildly enforceable lockdown' where residents were instructed to avoid going out their homes for non-essential reasons and limit the use of stores and facilities [3].

Based on previous pandemic, it is important to understand how facts and correct information about the health threat is disseminated and how the public processes and responds to this information [4], [5]. Proper and factual information have a critical role in controlling the spread of illness and managing uncertainty during an outbreak. Both formal and informal sources of information present a critical role in increasing situational awareness during public health emergencies. Although there were significant volume of news provided by public health officials, journalists and other sources, this huge amount of daily information does not just consist of correct information but also of fake news and misinformation. This is also applicable in Indonesia where recent study stated that there was an increase in public misinformation around basic coronavirus facts and there were a group of people who still did not understand misinformation regarding COVID-19 [6].

Consequently, to limit virus transmission, WHO continued to provide a guideline and recommend performing several protective behaviors against COVID-19, namely hand hygiene, using facial protection (e.g. mask), frequently cleaning and disinfecting surfaces, maintaining physical distances, avoiding crowded places, and restricting contact with people with fever or respiratory symptoms. The authorities in Indonesia with Ministry of Health have issued a health protocol for public to follow based on WHO guideline. At the individual level, they recommend frequent hand-washing, using facial protection (e.g., surgical mask and face shield) and the use of disinfectant (e.g., alcohol-based) are also endorsed [7]. Therefore, it is important to advocate to the public to prioritize implementing protective behaviors and understanding how the public respond about these measures

Previous study about epidemics showed that during the fight against severe acute respiratory syndrome (SARS), middle east respiratory syndrome (MERS) and Ebola outbreaks, individuals faced various mental health problems such as stress, depression, anxiety, distress, anger and grief [8]-[11]. Together with the strong person-to-person transmission capability of the virus, recent studies showed that the outbreak of COVID-19 has been reported to cause mental health problems [12]-[15]. Anxiety is one of the psychological problems that can emerged during COVID-19 outbreak and can be seen as an events that can raise concerns [16]-[18]. Few studies confirmed that people experienced high levels of anxiety since the outbreak of COVID-19 [19]-[24]. Another study involved 7,236 participants in China found that 35.1\% of participants reported anxiety symptoms, $20.1 \%$ reported depressive symptoms and $18.2 \%$ participants reported experienced poor sleep quality [25]. A previous study among 17,865 active users of a social media platform (Weibo) in China found that this epidemic has a strong impact on the psychological state: people showed higher negative emotions (e.g. anxiety, depression and indignation), higher sensitivity to social risks and lower positive emotions (e.g. happiness) and lower life satisfaction [26].

During COVID-19 epidemic, people experienced more negative emotions (e.g., anxiety and depression) and having less positive emotions, well-being and life satisfaction. Earlier researches also suggested that people's happiness level and well-being decreased from the onset of COVID-19 epidemic [27]-[31]. At the time of writing this paper (November 2020), many Indonesian people were living in some form of government-imposed social restriction. The authorities in Indonesia have maintained constant communication with the public about the status of COVID-19 outbreak. Considering the abrupt nature of the outbreak and the contagious power of the novel coronavirus (COVID-19), it is necessary for people to follow the protective behaviour and health protocol. Under these circumstances, people may show negative psychological reactions and affect their happiness and well-being. To the best of our knowledge, a research that systematically explores the role of perception of information about COVID-19 and protective behaviour in feelings of anxiety and happiness among Indonesian general population has never been conducted yet. Such data can be used for future psychological support and information provision by the government in a way that takes the emotions of the community into account. The present study aimed to assess the perception of the information provided about COVID-19 and the health protective behaviour, and to explore these as potential factors of feelings of anxiety and happiness among the general population in Indonesia during the period of a large scale social restriction in Indonesia due to COVID-19 outbreak. 


\section{RESEARCH METHOD}

\subsection{Participants}

We conducted an anonymous on-line cross-sectional survey from April 2-4, 2020 during a largescale social restriction, namely around one month after the COVID-19 outbreak in Indonesia. Eligible participants had to be Indonesia residents older than 18 years old and willing to participate in this study.

\subsection{Procedures}

This study was reviewed and approved by the Directorate of Research and Community Services of Universitas Padjadjaran, Indonesia. First, we constructed instruments to obtain information on demographic background (age, gender, region of residence, educational level and employment status), information provision of COVID-19, health protective behaviours, anxiety and happiness. Participants were recruited on the internet through a snowball sampling technique by spreading a survey link and they completed an online survey using the Google Form platform. All participants were voluntarily responded to the anonymous survey and provide their consent online on the first page of the survey. The survey procedure was clearly explained, and participants could interrupt or terminate participation at any time without explanation. Then, the participants would then be directed to complete an anonymous self-administered questionnaire.

To reach as many participants as possible all over the country, we relied on professional and personal networks of the researchers by reaching out to faculty members in university, students and Indonesian psychology profession association networks to broadcast and share the survey. The targeted participants were also encouraged to distribute the survey link to their personal contacts such as family members, friends or online chat groups. Two main platforms used in disseminating this survey were social media (e.g. Facebook, Twitter, Instagram) and WhatsApp. A standardised general description about the survey was given in the WhatsApp message or social media postings before the link was provided to the questionnaire. A total of 3,686 participants from 33 provinces in Indonesia took part in the survey.

\subsection{Survey instruments}

We developed a questionnaire that asked about the following areas: demographic data, information provision about COVID-19, health protective behaviours, and feeling of anxiety and happiness. The selection of measures was guided by our research questions and based on the measures used in fast-report articles on the COVID-19 outbreak that were accessible at the time of planning the study.

Sociodemographic data were collected on gender, age, residential location, education, and employment status. Information provision about COVID-19 was measured using a set of questions on several aspects, namely: i) Source of information (i.e. radio, television, website, official/government hotlines, and social media: Facebook, WhatsApp, Instagram); ii) Daily frequency of information searching (i.e. $<3$ times, 4-5 times, 6-10 times, and >10 times a day); iii) The amount of information provided; iv) Information about how the virus is transmitted; v) Information about protective behaviour to prevent the spread of the virus; vi) Information about screening/test for COVID-19; vii) Information about treatment of COVID-19; viii) Information about the impact of COVID-19; and ix) Information about referral hospitals or centres provided by Indonesian government. Participants were answered the questions on aspects 3 to 9 by a 4-point response scale $(1=$ none, $2=$ very little, $3=$ some and $4=a$ lot $)$.

Health protective behaviours were measured by questions on the following protective behaviours, namely: staying at home, washing hands, wearing a mask, sun bathing, consuming multivitamin, physical distancing, avoiding handshakes, avoid touching the face, implementing cough and sneezing etiquettes, and regular exercise at home. Participants were asked to answer in a 5-point response scale (range 1-5, 1=never; 5=always).

Anxiety and happiness were measured using two questions to describe their emotional condition within the last seven days. In order to measure feeling of anxiety, we included a question, "Are you feeling anxious?" ( $1=$ not at all to $5=$ very anxious). As for measuring happiness, we added a question"Are you feeling happy?" (1=not at all to $5=$ very happy). We adjusted the answer choices to a 5 -point scale for both questions.

\subsection{Data analysis}

Data analyses were carried out using the IBM SPSS Statistics version 22. We used descriptive statistics to describe the demographic characteristic of the participants and the scores obtained from the questionnaires. Associations between demographic characteristics, information provision about COVID-19, health protective behaviors, and feelings of anxiety and happiness were explored by t-test. Multiple regression analyses were performed to investigate the association between information provision about COVID-19 and health protective behaviors with feelings of anxiety and happiness. We did not apply a separate analysis on different levels of demographic or include those as interaction term. Further, Cohen's $d$ effect size was calculated for all comparisons, with $\mathrm{d}=$ =between 0.02 and 0.05 , $\mathrm{d}=$ between 0.05 and 
0.08 and $d \geq 0.08$ demonstrating a small, moderate, and large effect, respectively. All tests were two-tailed, with a significance level of $\mathrm{p}<0.05$.

\section{RESULTS AND DISCUSSION}

\subsection{Demographic background}

Data were obtained from 3,686 respondents from 33 Provinces in Indonesia. As shown in Table 1, the mean age of the participants was 37.1 years $(\mathrm{SD}=1.00)$. Most of participants were women and lived in West Java. Sixty-three percent of the participants $(63 \%)$ worked as private employee or government officer. The majority of participants $(79.4 \%)$ had a university education background.

Table 1. Demographic background of the respondents

\begin{tabular}{lc}
\hline \multicolumn{1}{c}{ Variable } & $\mathrm{n}(\%)$ \\
\hline Age $(\mathrm{M} \pm \mathrm{SD})$ & $37.13 \pm 11.00$ \\
Gender & $1,346(36.5 \%)$ \\
Male & $2,340(63.5 \%)$ \\
Female & \\
Residential location (province) & $1,947(52.8 \%)$ \\
West Java & $531(14.4 \%)$ \\
DKI Jakarta & $347(9.4 \%)$ \\
Banten & $128(3.5 \%)$ \\
East Java & $126(3.4 \%)$ \\
Central Java & $607(16.5 \%)$ \\
Other regions & \\
Employment status & $1,295(35.1 \%)$ \\
Private Employees & $1,031(27.9 \%)$ \\
Government officers & $499(13.5 \%)$ \\
House wife & $371(10.1 \%)$ \\
Self Employed & $334(9.1 \%)$ \\
Students & $34(0.9 \%)$ \\
Laborers & $122(3.3 \%)$ \\
Unemployed & \\
Highest education level & \\
Elementary and/or Secondary school & $431(11.7 \%)$ \\
College/Diploma & $330(9.0 \%)$ \\
University & $2,925(79.4 \%)$ \\
\hline
\end{tabular}

\subsection{Perception of information about COVID-19}

Considering participant's information sources about COVID-19, main news sources were social media, television, and websites in that order more than hotlines and radio. As presented in Figure 1, the majority of participants $(91 \%)$ reported that they received a lot of information about the outbreak through social media, such as Facebook, WhatsApp, and Instagram. In regard to the frequency of daily information searches, we found that $44.9 \%$ of the participants search information related to COVID-19 less than three times a day, 37\% of the participants seek information for four to five times a day, $9.9 \%$ of the participants search for the information roughly 6-10 times a day, and $8.2 \%$ of participants seek information about the outbreak more than ten times a day.

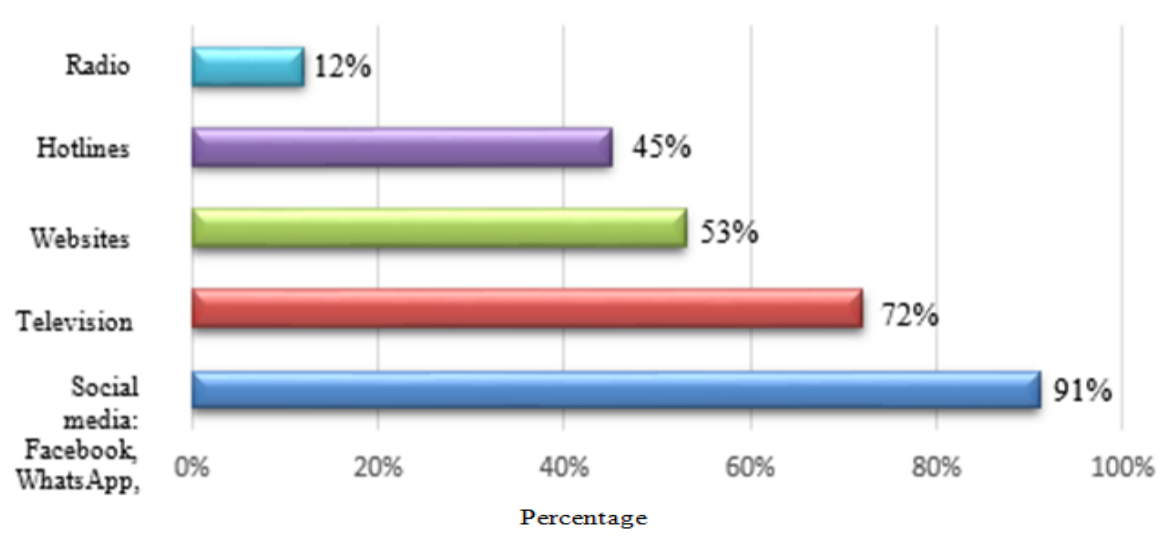

Figure 1. The percentages of frequency and type of source information about COVID-19 
Related to the aspect of information provision about COVID-19, we found that a considerable number of participants stated that they were satisfied with the amount of information provided (98\%) and they reported that there were adequate information about how the virus is transmitted (97\%) and information about protective behavior to prevent the spread of the virus $(96 \%)$ as shown in Figure 2. On the other hand, $54 \%$ of the participants said that there was no information available for them or they only receive a very limited information about screening test for COVID-19, and 49\% of them also reported that they did not receive any information at all or only get a very little info about the treatment of COVID-19.

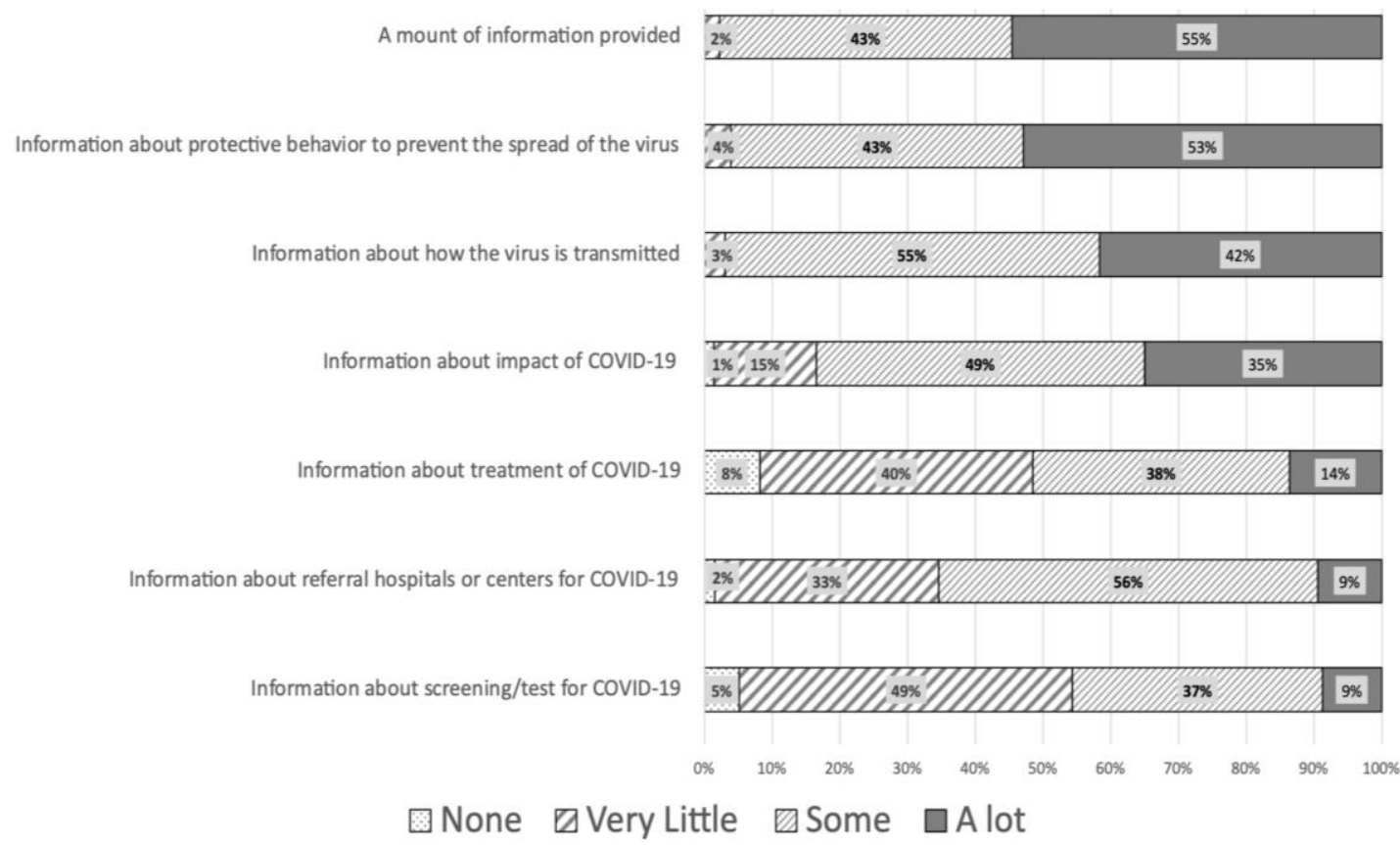

Figure 2. Perceived information about COVID-19

\subsection{Protective behaviors}

In regard to health protective behaviors, we found the following percentage of behaviors that were implemented 'often and always' by the participants, namely: 90\% of participants folowed cough and sneezing etiquettes, $89 \%$ avoided handshakes, $84 \%$ adopting physical distancing, $82 \%$ stayed at home, $78 \%$ wore a mask, $64 \%$ consumed multivitamin, $57 \%$ did not touch the face, $51 \%$ did sun bathing, $45 \%$ washed hands, and $33 \%$ of participants did regular exercise at home.

\subsection{Demographic variables related to anxiety and happiness score}

Table 2 describes frequency, means and statistics for demographic background, anxiety and happiness. We found that $72 \%$ of participans reported having feeling of anxiety and $23 \%$ of them expressed being unhappy. There was a significant difference in level of anxiety among male and female participants $(\mathrm{t}=-3.36, \mathrm{p}<0.01)$. Higher feeling of anxiety was found in female participants $(\mathrm{M}=4.05)$ compared to male participants $(M=3.94)$. Participants with laborer employment status expressed a higher feeling of anxiety $(\mathrm{M}=4.5)$ and had a lower score on happiness $(\mathrm{M}=2.53)$ compared to those with another employment status. We found significant difference in level of happiness based on education level $(t=17.48, p<0.01)$. Participants with elementary-high school background expressed significantly lower happiness score $(\mathrm{M}=2.85)$ than participants with college or university background $(\mathrm{M}=3.15)$.

\subsection{Perception of information about COVID-19 and protective behaviors related to feelings of anxiety and happiness}

Results from the multiple linear regression analyses as presented in Table 3 show that the higher frequency of daily information search about COVID-19 $(\beta=0.16$, p-value=0.01), higher amount of information about COVID-19 provided $(\beta=0.06$, $\mathrm{p}$-value=0.01), and higher amount of information about how the virus is transmitted $(\beta=0.06, \mathrm{p}$-value $=0.01)$ significantly predicted a higher feeling of anxiety. On the 
other hand, further information about screening test for COVID-19 $(\beta=-0.05, \mathrm{p}$-value $=0.05)$ and information about treatment of COVID-19 $(\beta=-0.05$, $\mathrm{p}$-value=0.05) significantly predicted a lower feeling of anxiety.

In regard of happiness, we found that higher frequency of daily information search about COVID-19 $(\beta=-0.08, \mathrm{p}$-value $=0.01)$, higher amount of information about COVID-19 provided $(\beta=-0.04, \mathrm{p}$-value $=0.05)$, and higher information about impact of COVID-19 $(\beta=-0.05$, p-value $=0.05)$ significantly predicted lower happiness. However, higher provision on information about protective behavior to prevent the spread of the virus $(\beta=0.06, \mathrm{p}$-value $=0.01)$, information about treatment of COVID-19 $(\beta=0.12, \mathrm{p}$-value $=0.01)$ and information about referral hospitals or centers for COVID-19 $(\beta=0.07, \mathrm{p}$-value $=0.01)$ were significantly predicted higher happiness.

Table 2. Frequency, means and statistics for demographic background, anxiety and happiness

\begin{tabular}{|c|c|c|c|c|c|}
\hline \multirow{2}{*}{ Variable } & \multirow{2}{*}{$\mathrm{f}(\%)$} & \multicolumn{2}{|c|}{ Anxiety } & \multicolumn{2}{|c|}{ Happiness } \\
\hline & & $\mathrm{M}(\mathrm{SD})$ & $\mathrm{t} / \mathrm{F}$ & $\mathrm{M}(\mathrm{SD})$ & $\mathrm{t} / \mathrm{F}$ \\
\hline \multicolumn{6}{|l|}{ Gender } \\
\hline Male & $1,346(36.5 \%)$ & $3.94(1.04)$ & $-3.36 * *$ & $3.13(1.02)$ & 0.93 \\
\hline Female & $2,340(63.5 \%)$ & $4.05(0.92)$ & & $3.10(0.96)$ & \\
\hline \multicolumn{6}{|l|}{ Employment status } \\
\hline Laborers & $34(0.9 \%)$ & $4.5(0.96)$ & $7.84 * *$ & $2.53(1.02)$ & $11.79 * *$ \\
\hline House wife & $499(13.5 \%)$ & $4.17(0.9)$ & & $3.14(0.97)$ & \\
\hline Students & $334(9.1 \%)$ & $3.93(1)$ & & $2.85(0.97)$ & \\
\hline Private employees & $1,295(35.1 \%)$ & $4.03(0.94)$ & & $3.06(0.98)$ & \\
\hline Government officers & $1,031(27.9 \%)$ & $3.79(1.03)$ & & $3.50(0.93)$ & \\
\hline Self employed & $371(10.1 \%)$ & $3.82(1.08)$ & & $3.19(1.01)$ & \\
\hline Unemployed & $122(3.3 \%)$ & $3.93(1.08)$ & & $3.18(0.98)$ & \\
\hline \multicolumn{6}{|l|}{ Education level } \\
\hline Elementary-High school & $431(11.7 \%)$ & $4.1(1.01)$ & 2.5 & $2.85(1.07)$ & $17.48^{* *}$ \\
\hline College/Diploma & $330(9.0 \%)$ & $4.03(1.13)$ & & $3.15(1.11)$ & \\
\hline University & $2,925(79.4 \%)$ & $3.99(0.94)$ & & $3.15(0.95)$ & \\
\hline
\end{tabular}

Table 3. Regression analyses of information provision associated with feeling anxiety and happiness

\begin{tabular}{|c|c|c|c|c|c|}
\hline \multirow{2}{*}{ Indicators } & \multirow{2}{*}{$\mathrm{M}(\mathrm{SD})$} & \multicolumn{2}{|c|}{ Feeling anxiety } & \multicolumn{2}{|c|}{ Happiness } \\
\hline & & R squared & Beta & $\mathrm{R}$ squared & Beta \\
\hline $\begin{array}{l}\text { Frequency of daily information searching about } \\
\text { COVID-19 }\end{array}$ & 1.81 & 0.041 & $0.16^{* *}$ & 0.017 & $-0.08 * *$ \\
\hline $\begin{array}{l}\text { Amount of information about COVID-19 } \\
\text { provided }\end{array}$ & 3.39 & & $0.06 * *$ & & $-0.04 *$ \\
\hline Information about how the virus is transmitted & 3.52 & & $0.06 * *$ & & -0.04 \\
\hline $\begin{array}{l}\text { Information about protective behavior to } \\
\text { prevent the spread of the virus }\end{array}$ & 3.49 & & -0.03 & & $0.06^{* *}$ \\
\hline Information about screening/test for COVID-19 & 2.49 & & $-0.05^{*}$ & & 0.02 \\
\hline Information about treatment of COVID-19, & 2.57 & & $-0.05^{*}$ & & $0.12 * *$ \\
\hline Information about impact of COVID-19, & 3.17 & & 0.00 & & $-0.05^{*}$ \\
\hline $\begin{array}{l}\text { Information about referral hospitals or centers } \\
\text { for COVID- } 19\end{array}$ & 2.73 & & -0.02 & & $0.07 * *$ \\
\hline
\end{tabular}

Multiple linear regression analyses were also used to evaluate association between health protective behaviors and feeling of anxiety and happiness among participants. As presented in Table 4, we found that staying at home $(\beta=0.04$, $\mathrm{p}$-value $=0.05)$, washing hands $(\beta=0.09$, p-value $=0.01)$, wearing a mask $(\beta=0.12, \mathrm{p}$ value $=0.01)$, sun bathing $(\beta=0.05, \mathrm{p}$-value $=0.05)$, avoiding handshakes $(\beta=0.07, \mathrm{p}$-value $=0.01)$ were significantly associated with higher feeling of anxiety. On the other hand, doing regular exercise at home $(\beta=-0.10, \mathrm{p}$-value $=0.05)$ was associated with lower feeling of anxiety. Regarding to happiness, we found that regular exercise at home $(\beta=0.04, \mathrm{p}$-value $=0.05)$, physical distancing $(\beta=0.09, \mathrm{p}$-value $=0.01)$ and implementing cough and sneezing etiquettes $(\beta=0.09$, $\mathrm{p}$-value $=0.01)$ were significantly and positively associated with happiness.

\subsection{Discussion}

The pandemic COVID-2019 has led to a serious impact on many aspects and become a center of attention of the world. This study found that the majority of participants search and obtain information about COVID-19 from social media (i.e. Facebook, WhatsApp, Instagram) and television. Previous studies found that after first state COVID-19 case announcements, there was a significant increase in the extent to which people seek out information about the epidemic through the internet and several online sources [32], [33]. A study in China about health communication through news media during the early stage of the COVID-19

Perception of information about COVID-19 and protective behaviours in relation ... (Aulia Iskandarsyah) 
Outbreak found the top three popular themes of news were prevention and control procedures $(32.6 \%)$, medical treatment and research (16.6\%), and global/local social/economic influences (11.8\%) [34]. The reason why social media emerged as the main source of information about COVID-19 is because social media has opened new channel for rapid communication and information circulation [35], [36]. The expansion of internet network and social media has exceptionally changed how the information is delivered and providing the public with timely news coverage.

Table 4. Regression analyses of health protective behaviors associated with feeling anxiety and happiness

\begin{tabular}{|c|c|c|c|c|c|}
\hline \multirow{2}{*}{ Indicators } & \multirow{2}{*}{$\mathrm{M}(\mathrm{SD})$} & \multicolumn{2}{|c|}{ Feeling anxiety } & \multicolumn{2}{|c|}{ Happiness } \\
\hline & & $\mathrm{R}$ squared & Beta & $\mathrm{R}$ squared & Beta \\
\hline Staying at home & $4.16(0.96)$ & 0.057 & $0.04 *$ & 0.03 & 0.05 \\
\hline Washing hands & $3.39(1.11)$ & & $0.09 * *$ & & 0.01 \\
\hline Wearing a mask & $4.19(1.11)$ & & $0.12 * *$ & & $-0.05 * *$ \\
\hline Regular exercise at home & $3.05(1.14)$ & & $-0.10 *$ & & $0.12 * *$ \\
\hline Sun bathing & $3.47(1.16)$ & & $0.05 *$ & & 0.03 \\
\hline Consuming multivitamin & $3.76(1.2)$ & & 0.01 & & 0.02 \\
\hline Physical distancing & $4.27(0.86)$ & & 0.00 & & $0.05^{*}$ \\
\hline Avoiding handshakes & $4.55(0.82)$ & & $0.07 * *$ & & $-0.06 * *$ \\
\hline Avoid touching the face & $3.65(1)$ & & 0.02 & & $-0.06 * *$ \\
\hline Implementing cough and sneezing etiquettes & $4.48(0.76)$ & & 0.02 & & $0.05 * *$ \\
\hline
\end{tabular}
$* \mathrm{p}<0.05 ; * * \mathrm{p}<0.01$

Information seeking at the time of an outbreak is prevalent response. During Ebola and H1N1 epidemic, there was an increase in monitoring and information seeking about the health crisis [37]. We found that almost half of participants $(44.9 \%)$ searched information related to COVID-19 less than three times a day. Only small percentages of participants appear to search for more than 10 times a day. The low rate of daily information seeking could be viewed from a positive angle as a greater exposure of news or information about the outbreak may bring about more psychological distress [38], [39]. Despite the fact that dissemination of information is essential for staying informed, the coverage of current epidemic did negatively affect the psychological well-being in Indonesia, thus lessen the daily information consumption about COVID-19 could act as a protective factor from negative emotional responses. Regarding satisfaction to information provision, the majority of participants stated that they satisfied with the amount of information provided, specifically about how the virus is transmitted and protective behavior to prevent the spread of the virus but less satisfied with available information about the screening test and treatment of COVID-19.

In regard to health protective behavior to prevent the spreading of the virus, we found a high to moderate percentages of participants implementing cough and sneezing etiquettes, avoiding handshakes, physical distancing, staying at home, and wearing a mask. This findings is in line with a study involving 3,464 general population in Indonesia that found the majority of participants show good practices to prevent and mitigate the COVID-19 pandemic [40]. Protective behaviors that tend to be implemented less frequently were washing hands and doing regular exercise at home. The small percentage of participants who practised hand washing (less than 50\%) was quite concerning, considering washing hand with soap and water has been proven to effectively curb the virus [41]. In general, sanitation conditions in Indonesia are not sufficient. Previous data from Central Bureau of Statistics in 2019 showed that only $76.07 \%$ of the national population has access to hand washing facilities with soap and clean water, and even lower percentages for region outside urban areas [42]. Based on this statistics, none of the country's 34 provinces reported figure above 90 percent, not even our sample's residential locations, which recorded at most $73 \%$ to $81 \%$ population with access to adequate washing facilities.

We identified that $72 \%$ of participants reported having feeling of anxiety and $23 \%$ of them reported being unhappy. Female participants were found had significant higher feeling of anxiety compared to male participants. This finding was suported by earlier COVID-19 research where females participants were more likely to experience anxiety than males [43]. However, women might be more anxious in general regardless of COVID-19 pandemic. Gender differences in anxiety could be related to socialization of different gender roles for men and women, i.e women are more inclined to be open about their negative feelings than men [44]. Nonetheless, the role of socialization proccess add to suspectibility of anxiety is complicated.

Participants who had laborer employment experienced higher feeling of anxiety and lower score on happiness. People's level of anxiety during the COVID-19 was not exclusively dealing with health impact in general but also extends to socioeconomic impacts of the epidemic [45]. The consequences from public health measure against the COVID-19 such as job losses, financial insecurities, and disruption to daily activities can led to negative impact on people's mental health and their well-being [46], [47]. People, who have an unstable job position, receive unpredictable income or experienced loss of household income may be 
vulnerable to feel more anxious and experience lower well-being due to the uncertainty of the epidemic. Economic anxiety can also apply to people who are economically vulnerable and insecure, even when there is no virus outbreak. Moreover, participants with elementary-high school background reported significantly lower happiness score. People's emotional experiences during the outbreak can be fluctuated through the course of the pandemic and the nature of public health measure applied.

In this study, it was found that frequent daily information searching about COVID-19, higher amount of information about COVID-19 provided, and grater amount of information about how the virus is transmitted and the impacat of COVID-19 significantly predicted a higher feeling of anxiety and lower happiness. Disproportionate and constant informations about COVID-19 (i.e., threat, infection and death rate) could make people feel more anxious about the current situation which can have an adverse effect on their psychological health. Our finding was confirmed by previous study which showed that information searching about COVID-19 might be related to fear-related emotions [48]. The level of knowledge of COVID19 was correlated with level of anxiety and sensitiveness to some information sources [49].

Despite the dissemination of information is essential measure, the persistent exposure to COVID-19 in mass media can increase the levels of anxiety and fear-related emotions [50]-[52]. Individuals who consuming and received greater amounts of information about COVID-19 from the media had a higher level of anxiety [53]-[55]. Previous research also showed that, the more people get exposed to news content associated with COVID-19 especially on social media, the higher tendency to ruminate over the information [56]. Information seeking about COVID-19 during the pandemic from the internet also correlated with greater symptoms of anxiety and depression [57]. These findings could explain association between information exposure about COVID-19 and feeling of anxiety during the outbreak.

On the other hand, greater amount of information about screening/test for COVID-19 and information about treatment of COVID-19 predicted a lower feeling of anxiety. Information that highlighted the benefits of engaging in certain behavior, focus on protecting oneself and others, and appeal to scientific norms more likely to be persuasive and accepted by public [58]. For this reason, messages that provided information about screening and treatment of the disease might be perceived as useful in helping people lower their negative emotional responses. By receiving this information, people know that the viral infection can be detected and treated early to prevent more severe complication from the disease. This type of informations give people a sense of control amidst of chaos due to the pandemic, it is generally known that the feeling of having control on the stressor can reduce stress. Building up the publicity and transparency of COVID-19 knowledge and careful measures adopted to prevent the spread of COVID-19 or information about the number of people who have recovered and the progress of treatment and vaccines can reduce the anxiety level of the public [59].

We found that information about protective behaviours, referral hospitals for COVID-19 and treatment of COVID-19 can predict higher happiness. It can due to people's supportive attitude toward credibility of information updates and trust in the epidemic control at the time of public health emergency. The type and content of information about current pandemic can determine different emotional responses among people. Higher perceived of knowledge was related with a higher sense of control, which lead to differences in emotional well being during the early stage of the pandemic. Our finding showed that protective behaviours, namely staying at home, washing hands, wearing a mask, sun bathing, avoiding handshakes were associated with greater anxiety. This data could explain the role of anxiety in enforcing precautionary behaviours [60]. Having fear of getting infected can make people implement certain behaviours that reduce the risk of catching the virus, but these worries can also arise from self-protective behavior. It can be said that people who engage in protective behaviours against the spread of the virus were motivated by the feeling of anxiety they experienced. Study among Taiwanese showed that individuals who reported worsening psychological health during the pandemic were more likely to implement protective behaviors (avoiding crowded places and wearing mask) [61].

Our result showed that regular exercise at home was associated with lower feeling of anxiety and predicted happiness. Physical activity is recommended during the COVID-19 pandemic due its multiple benefits on physical health (boost immune system) and mental health (improving mood) [62]. People who do sport are generally happier and have a better well-being, one of the reason for this relationship is that excerise was perceived as being pleasurable [63], [64]. This result may not be resulted within the context of COVID19 pandemic solely.

We also found protective behaviors were associated with happiness. Implementing protective behaviors can make people feel happier probably because those behaviors can make them feel safer from virus infection amid the pandemic. Perceived personal risk and perceiving health measures as effective associated with reported adoption of protective behaviors during current and past pandemic [65], [66].

Our study has several limitations that should be considered when interpreting the findings. The study used cross-sectional design which can't explain the causality relationship between variables. Future studies can broaden this research by using longitudinal or experimental research designs to explore causal 
links between psychological variables and concern about the COVID-19. As this study used a snowball sampling technique, we cannot measure the response rate of the participants. Our participants were limited to internet users and tech savy which makes many underprivileges populations might not be able to participate in the study. Another limitation might be that people give socially desirable answers. It is important for future study to perform a more in-depth study, using diaries to note protective behaviours might be recommended. Additionally, some items of the questionnaire were introduced by us without any prior studies. Thefore, a more comprehensive assessment of instrument psychometric properties are needed. It is desirable to expand further research and consider different variables, such as the physical, psychological and socioeconomic impact, the timing of the survey in the course of pandemic, and the extend of public health measures in Indonesia. Nevertheless, we used a quite large samples in this study and some predictors were significantly predicted the feelings of anxiety and happiness, our results can be useful to design a large scale intervention.

\section{CONCLUSION}

The majority of the Indonesian people implemented protective measures in particular regarding sneezing and coughing etiquette and social distancing. Greater amount of information about COVID-19 and applying protective behaviour were associated with higher anxiety. Taking protective measures appeared to be related with feeling of happiness. Our study should be replicated in other populations in Indonesia (especially rural and outside Java). Nevertheless, our research has given suggestions about the information provision, application of preventive measure and the factors associated with feelings of anxiety and happiness. This outcome can be valuable to design a psychological intervention for vulnerable groups during and after the COVID-19 pandemic.

\section{ACKNOWLEDGEMENTS}

The authors would like to thank all participants for their generous participation in this study. This research was funded by COVID-19 Research Grant from Universitas Padjadjaran, grant number 1735/UN6.3.1/LT/2020.

\section{REFERENCES}

[1] C. Huang et al., "Clinical features of patients infected with 2019 novel coronavirus in Wuhan, China," Lancet (London, England), vol. 395, no. 10223, pp. 497-506, Feb. 2020, doi: 10.1016/s0140-6736(20)30183-5.

[2] World Health Organization, "Indonesia: WHO Coronavirus Disease (COVID-19)," 2021. https://covid19.who.int/region/searo/country/id (accessed Nov. 12, 2021).

[3] T. Yamamoto, C. Uchiumi, N. Suzuki, J. Yoshimoto, and E. Murillo-Rodriguez, "The psychological impact of 'mild lockdown' in japan during the COVID-19 pandemic: a nationwide survey under a declared state of emergency," Int. J. Environ. Res. Public Health, vol. 17, no. 24, p. 9382, Dec. 2020, doi: 10.3390/ijerph17249382.

[4] L. Lin, E. Savoia, F. Agboola, and K. Viswanath, "What have we learned about communication inequalities during the H1N1 pandemic : a systematic review of the literature," BMC Public Health, vol. 14, no. 1, pp. 1-13, 2014.

[5] L. Lin, M. Jung, R. F. McCloud, and K. Viswanath, "Media use and communication inequalities in a public health emergency: a case study of 2009-2010 pandemic influenza A virus subtype H1N1," Public Health Rep., vol. 129 Suppl, no. Suppl 4, pp. 49-60, 2014, doi: 10.1177/00333549141296S408.

[6] N. M. Nasir and M. I. Nurmansyah, "Misinformation related to COVID-19 in Indonesia," J. Adm. Kesehat. Indones., vol. 8, no. 2, pp. 51-59, 2020, doi: 10.20473/jaki.v8i2.2020.51-59.

[7] Indonesian Ministry of Health, "Prevention and control guidelines corona virus disease 2019 (COVID-19)." 2020. https://covid19.go.id/storage/app/media/Regulasi/2020/Juli/KMK No. HK.01.07-MENKES-413-2020 ttg Pedoman Pencegahan dan Pengendalian COVID-19.pdf (accessed Nov. 12, 2021).

[8] J. M. Cénat et al., "Prevalence of mental health problems in populations affected by the Ebola virus disease: a systematic review and meta-analysis," Psychiatry Res., vol. 289, no. April, p. 113033, 2020, doi: 10.1016/j.psychres.2020.113033.

[9] M. F. Jalloh et al., "Impact of Ebola experiences and risk perceptions on mental health in Sierra," BMJ Glob. Heal., vol. 3, p. e000471, 2018, doi: 10.1136/bmjgh-2017-000471.

[10] H. Jeong et al., "Mental health status of people isolated due to Middle East Respiratory Syndrome," Epidemiol. Health, vol. 38, p. e2016048, 2016, doi: 10.4178/epih.e2016048.

[11] S. Kamara, A. Walder, J. Duncan, A. Kabbedijk, P. Hughes, and A. Muana, "Mental health care during the Ebola virus disease outbreak in Sierra Leone," Bull. World Health Organ., vol. 95, pp. 842-847, 2017, doi: 10.2471/BLT.16.190470.

[12] L. Duan and G. Zhu, "Psychological interventions for people affected by the COVID-19 epidemic," The Lancet Psychiatry, vol. 7, no. 4, pp. 300-302, 2020, doi: 10.1016/S2215-0366(20)30073-0.

[13] L. Kang et al., "The mental health of medical workers in Wuhan, China dealing with the 2019 novel coronavirus," The Lancet Psychiatry, vol. 7, no. 3, p. 14, 2020, doi: 10.1016/S2215-0366(20)30047-X.

[14] N. Liu et al., "Prevalence and predictors of PTSS during COVID-19 outbreak in China hardest-hit areas: gender differences matter," Psychiatry Res., vol. 287, p. 112921, May 2020, doi: 10.1016/j.psychres.2020.112921.

[15] J. Shigemura, R. J. Ursano, J. C. Morganstein, M. Kurosawa, and D. M. Benedek, "Public responses to the novel 2019 coronavirus (2019-nCoV) in Japan: Mental health consequences and target populations," Psychiatry Clin. Neurosci., vol. 74, no. 4, pp. 281-282, Apr. 2020, doi: 10.1111/pcn.12988.

[16] C. Wang et al., "A longitudinal study on the mental health of general population during the COVID-19 epidemic in China," Brain. Behav. Immun., vol. 87, pp. 40-48, Jul. 2020, doi: 10.1016/j.bbi.2020.04.028. 
[17] C. Wang et al., "Immediate psychological responses and associated factors during the initial stage of the 2019 coronavirus disease (COVID-19) epidemic among the general population in China," Int. J. Environ. Res. Public Health, vol. 17, no. 5, p. 1729, Mar. 2020, doi: 10.3390/ijerph17051729.

[18] W. Cao, Z. Fang, G. Hou, M. Han, X. Xu, and J. Dong, "The psychological impact of the COVID-19 epidemic on college students in China," Psychiatry Res., vol. 287, 2020, doi: 10.1016/j.psychres.2020.112934.

[19] Y. Xiang et al., "Timely mental health care for the 2019 novel coronavirus outbreak is urgently needed," The Lancet Psychiatry, vol. 7, no. 3, pp. 228-229, 2020, doi: 10.1016/S2215-0366(20)30046-8.

[20] L. Huang, W. Lei, F. Xu, H. Liu, and L. Yu, "Emotional responses and coping strategies in nurses and nursing students during Covid-19 outbreak: A comparative study," PLoS One, vol. 15, no. 8, p. e0237303, Aug. 2020, doi: 10.1371/JOURNAL.PONE.0237303.

[21] S. Islam, M. Z. Zannatul, and M. N. Potenza, "Panic and generalized anxiety during the COVID-19 pandemic among Bangladeshi people: An online pilot survey early in the outbreak," J. Affect. Disord., vol. 276, no. April, pp. 30-37, 2020, doi: 10.1016/j.jad.2020.06.049.

[22] M. A. Man et al., "Disease perception and coping with emotional distress during COVID-19 Pandemic: A Survey Among Medical Staff," Int. J. Environ. Res. Public Health, vol. 17, no. 13, pp. 1-12, 2020, doi: 10.3390/ijerph17134899.

[23] A. Moghanibashi-mansourieh, "Assessing the anxiety level of Iranian general population during COVID-19 outbreak," Asian J. Psychiatr., vol. 51, no. March, p. 102076, 2020, doi: 10.1016/j.ajp.2020.102076.

[24] S. Özdin and Ş. Bayrak Özdin, "Levels and predictors of anxiety, depression and health anxiety during COVID-19 pandemic in Turkish society: The importance of gender," Int. J. Soc. Psychiatry, vol. 66, no. 5, pp. 504-511, Aug. 2020, doi: $10.1177 / 0020764020927051$.

[25] Y. Huang and N. Zhao, "Mental health burden for the public affected by the COVID-19 outbreak in China: Who will be the highrisk group?," Psychol. Health Med., pp. 1-12, 2020, doi: 10.1080/13548506.2020.1754438.

[26] S. Li, Y. Wang, J. Xue, N. Zhao, and T. Zhu, "The impact of COVID-19 epidemic declaration on psychological consequences: a study on active weibo users," Int. J. Environ. Res. public Heal., vol. 17, no. 6, pp. 1-9, 2020, doi: 10.3390/ijerph17062032.

[27] S. Every-palmer et al., "Psychological distress, anxiety, family violence, suicidality, and wellbeing in New Zealand during the COVID-19 lockdown: A cross-sectional study," PLoS One, vol. 15, no. 11, pp. 1-19, 2020, doi: 10.1371/journal.pone.0241658.

[28] A. Gori, E. Topino, and A. Di Fabio, "The protective role of life satisfaction, coping strategies and defense mechanisms on perceived stress due to COVID-19 emergency: a chained mediation model," PLoS One, vol. 15, no. 11, pp. 1-11, 2020, doi: 10.1371/journal.pone.0242402.

[29] T. Greyling, S. Rossouw, and T. Adhikari, "A tale of three countries: what is the relationship between covid-19, lockdown and happiness?," South African J. Econ., vol. 89, no. 1, pp. 25-43, Mar. 2021, doi: 10.1111/saje.12284.

[30] T. Greyling, S. Rossouw, and T. Adhikari, "Happiness-lost: Did Governments make the right decisions to combat COVID-19?," GLO Discuss. Pap., pp. 1-28, 2020.

[31] H. Yang and J. Ma, "How an epidemic outbreak impacts happiness: factors that worsen (vs. protect) emotional well-being during the coronavirus pandemic," vol. 289, p. 113045, Jul. 2020, doi: 10.1016/j.psychres.2020.113045.

[32] A. I. Bento, T. Nguyen, C. Wing, F. Lozano-rojas, Y. Ahn, and K. Simon, "Evidence from internet search data shows information-seeking responses to news of local COVID-19 cases," Proc. Natl. Acad. Sci., vol. 117, no. 21, pp. 11220-11222, 2020, doi: 10.1073/pnas.2005335117.

[33] Y. Wang, Y. Di, J. Ye, and W. Wei, "Study on the public psychological states and its related factors during the outbreak of coronavirus disease 2019 (COVID-19) in some regions of China," Psychol. Health Med., vol. 26, no. 1, pp. 13-22, Jan. 2021, doi: $10.1080 / 13548506.2020 .1746817$

[34] Q. Liu et al., "Health communication through news media during the early stage of the COVID-19 outbreak in China: a digital topic modeling approach (Preprint)," J. Med. Internet Res., 2020, doi: 10.2196/19118.

[35] T. A. Kass-Hout and H. Alhinnawi, "Social media in public health," Br. Med. Bull., vol. 108, no. 1, pp. 5-24, Dec. 2013, doi: $10.1093 / \mathrm{bmb} / \mathrm{ldt} 028$

[36] D. Toppenberg-Pejcic, J. Noyes, T. Allen, N. Alexander, M. Vanderford, and G. Gamhewage, "Emergency risk communication: lessons learned from a rapid review of recent gray literature on Ebola, Zika, and Yellow Fever," Health Commun., vol. 34, no. 4, pp. 437-455, Mar. 2019, doi: 10.1080/10410236.2017.1405488.

[37] Q. H. Chew, K. C. Wei, S. Vasoo, H. C. Chua, and K. Sim, "Narrative synthesis of psychological and coping responses towards emerging infectious disease outbreaks in the general population: practical considerations for the COVID-19 pandemic," Singapore Med. J., vol. 61, no. 7, pp. 350-356, 2020, doi: 10.11622/smedj.2020046.

[38] M. Y1ldırım and A. Güler, "Positivity explains how COVID-19 perceived risk increases death distress and reduces happiness," Pers. Individ. Dif., no. January, 2020, doi: doi: 10.1016/j.paid.2020.110347.

[39] N. Zhao and G. Zhou, "Social media use and mental health during the COVID-19 pandemic: moderator role of disaster stressor and mediator role of negative affect," Appl. Psychol. Heal. Well-Being, pp. 1-20, 2020, doi: 10.1111/aphw.12226.

[40] Y. Yodang et al., "Knowledge, attitudes, and practices of indonesian residents regarding covid-19: A national cross-sectional survey," Int. J. Public Heal. Sci., vol. 10, no. 2, pp. 418-427, 2021, doi: 10.11591/ijphs.v10i2.20722.

[41] K. Amgain, S. Neupane, L. Panthi, and P. Thapaliya, "Myths versus Truths regarding the novel coronavirus disease (COVID-2019) Outbreak," J. Karnali Acad. Heal. Sci., vol. 3, no. 1, pp. 1-6, 2020.

[42] Badan Pusat Statistik, "Proportion of households owning handwashing facilities with soap and water by Province (Percent)." 2019. https://www.bps.go.id/indicator/152/1273/1/proporsi-populasi-yang-memiliki-fasilitas-cuci-tangan-dengan-sabun-dan-airmenurut-provinsi.html (accessed Nov. 12, 2021)

[43] M. Malesza and M. C. Kaczmarek, "Predictors of anxiety during the COVID-19 pandemic in Poland," Pers. Individ. Dif., vol. 170, p. 110419, Feb. 2021, doi: 10.1016/j.paid.2020.110419.

[44] A. K. Zalta and D. L. Chambless, "Understanding gender differences in anxiety: the mediating effects of instrumentality and mastery,” Psychol. Women Q., vol. 36, no. 4, pp. 488-499, 2012, doi: 10.1177/0361684312450004.

[45] S. Taylor, C. A. Landry, M. M. Paluszek, G. S. Rachor, J. Gordon, and G. Asmundson, "Worry, avoidance, and coping during the COVID-19 pandemic: a comprehensive network analysis," J. Anxiety Disord., vol. 76, no. August, pp. 1-7, 2020, doi: 10.1016/j.janxdis.2020.102327.

[46] S. Galea, R. M. Merchant, and N. Lurie, "The mental health consequences of COVID-19 and physical distancing the need for prevention and early intervention," JAMA Intern. Med., vol. 180, no. 6, pp. 817-818, 2020, doi: 10.1002/da.20838.

[47] C. K. T. Lima et al., "The emotional impact of Coronavirus 2019-nCoV (new Coronavirus disease)," Psychiatry Res., vol. 287, p. 112915, 2020, doi: 10.1016/j.psychres.2020.112915.

[48] H. Du, J. Yang, R. B. King, L. Yang, and P. Chi, "COVID-19 increases online searches for emotional and health-related terms," Appl. Psychol. Heal. Well-Being, vol. 12, no. 4, pp. 1039-1053, Dec. 2020, doi: 10.1111/aphw.12237.

Perception of information about COVID-19 and protective behaviours in relation ... (Aulia Iskandarsyah) 
[49] A. Shiina, T. Niitsu, O. Kobori, K. Idemoto, and T. Hashimoto, "Brain, behavior, \& immunity-health relationship between perception and anxiety about COVID-19 infection and risk behaviors for spreading infection: a national survey in Japan," Brain, Behav. Immun. - Heal., vol. 6, no. June, pp. 6-18, 2020, doi: 10.1016/j.bbih.2020.100101.

[50] J. Guo, X. L. Feng, X. H. Wang, and M. H. Van Ijzendoorn, "Coping with COVID-19: exposure to COVID-19 and negative impact on livelihood predict elevated mental health problems in Chinese adults," Int. J. Environ. Res. Public Health, vol. 17, no. 18, pp. 1-18, 2020, doi: 10.3390/ijerph17113857.

[51] R. R. Thompson, D. R. Garfin, E. A. Holman, and R. C. Silver, "Distress, worry, and functioning following a global health crisis : a national study of americans' responses to Ebola," Clin. Psychol. Sci., vol. 5, no. 3, pp. 513-521, 2017, doi: $10.1177 / 2167702617692030$.

[52] J. Van den Bulck and K. Custers, "Television exposure is related to fear of avian flu, an Ecological Study across 23 member states of the European Union," Eur. J. Public Health, vol. 19, no. 4, pp. 370-374, 2009, doi: 10.1093/eurpub/ckp061.

[53] G. Akdeniz, M. Kavakci, M. Gozugok, S. Yalcinkaya, A. Kucukay, and B. Sahutogullari, "A survey of attitudes, anxiety status, and protective behaviors of the university students during the COVID-19 outbreak in Turkey," Front. Psychiatry, vol. 11, pp. 1-9, 2020, doi: 10.3389/fpsyt.2020.00695.

[54] A. Ebrahim, Z. Saif, M. Buheji, N. AlBasri, F. Al-Husaini, and H. Jahrami, "COVID-19 information-seeking behavior and anxiety symptoms among parents," OSP J. Heal. Care Med., vol. 1, no. 1, pp. 1-9, 2020.

[55] Y. Feng, M. Zong, Z. Yang, W. Gu, D. Dong, and Z. Qiao, "When altruists cannot help: the influence of altruism on the mental health of university students during the COVID-19 pandemic," Global. Health, vol. 16, no. 1, pp. 1-8, 2020, doi: 10.1186/s12992-020-00587-y.

[56] S. K. Brooks et al., "Rapid Review The psychological impact of quarantine and how to reduce it: rapid review of the evidence," Lancet, vol. 395, no. 10227, pp. 912-920, 2020.

[57] R. Sigurvinsdottir, I. E. Thorisdottir, and H. F. Gylfason, "The impact of COVID-19 on mental health: the role of locus on control and internet use," Int. J. Environ. Res. Public Health, vol. 17, no. 19, pp. 1-15, 2020, doi: 10.3390/ijerph17196985.

[58] J. J. Van Bavel et al., "COVID-19 pandemic response," Nat. Hum. Behav., vol. 4, no. May, pp. 460-471, 2020, doi: $10.1038 / \mathrm{s} 41562-020-0884-\mathrm{Z}$

[59] S.-J. Zhou et al., "Prevalence and socio-demographic correlates of psychological health problems in Chinese adolescents during the outbreak of COVID-19," Eur. Child Adolesc. Psychiatry, pp. 749-758, 2020, doi: 10.1007/s00787-020-01541-4.

[60] P. W. Wirtz, C. A. Rohrbeck, and K. M. Burns, "Anxiety effects on disaster precautionary behaviors: a multi-path cognitive model," J. Health Psychol., vol. 24, no. 10, pp. 1401-1411, 2019, doi: 10.1177/1359105317720277.

[61] P. Wang, N. Ko, Y. Chang, C. Wu, and W. Lu, "Subjective deterioration of physical and psychological health during the COVID-19 pandemic in Taiwan: their association with the adoption of protective behaviors and mental health problems," Int. J. Environ. Res. Public Health, vol. 17, no. 18, pp. 1-18, 2020, doi: 10.3390/ijerph17186827.

[62] M. J. Dwyer, M. Pasini, S. De Dominicis, and E. Righi, "Physical activity: benefits and challenges during the COVID-19 pandemic," Scand. J. Med. Sci. Sports, vol. 30, no. 7, pp. 1291-1294, Jul. 2020, doi: 10.1111/sms.13710.

[63] P. Dolan, G. Kavetsos, and I. Vlaev, "The happiness workout," Soc. Indic. Res., vol. 119, no. 3, pp. 1363-1377, 2013, doi: 10.1007/s11205-013-0543-0.

[64] S. Rasciute and P. Downward, "Health or mappiness? what is the impact of physical activity on the individual ?," Kyklos, vol. 63, no. 2, pp. 256-270, 2010, doi: 10.1111/j.1467-6435.2010.00472.x.

[65] Q. Liao, B. J. Cowling, W. W. T. Lam, D. M. W. Ng, and R. Fielding, “Anxiety, worry and cognitive risk estimate in relation to protective behaviors during the 2009 influenza A/H1N1 pandemic in Hong Kong: ten cross-sectional surveys," BMC Infect. Dis., vol. 14, no. 1, pp. 1-11, 2014.

[66] J. H. Zickfeld, T. W. Schubert, A. K. Herting, J. Grahe, and K. Faasse, "Correlates of health-protective behavior during the initial days of the COVID-19 Outbreak in Norway,” Front. Psychol., vol. 11, pp. 1-19, 2020, doi: 10.3389/fpsyg.2020.564083.

\section{BIOGRAPHIES OF AUTHORS}

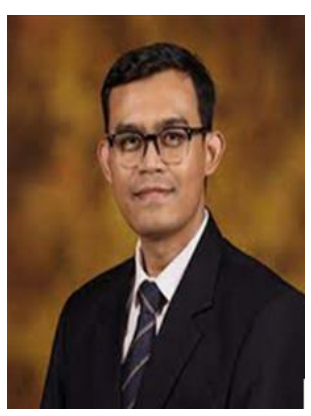

Aulia Iskandarsyah (D) SC $\mathrm{S}$ is a health and clinical psychologist who currently works as a lecturer and researcher at the Department of Clinical Psychology, Faculty of Psychology Universitas Padjadjaran, Indonesia. His expertise and research focus on clinical and health psychology, psychotherapy, qualitative research and mixed-method, in particular on health behavior, behavior change, psychosocial problem related to illness, psycho-education, quality of life, and well-being. He can be contacted at email: a.iskandarsyah@unpad.ac.id.

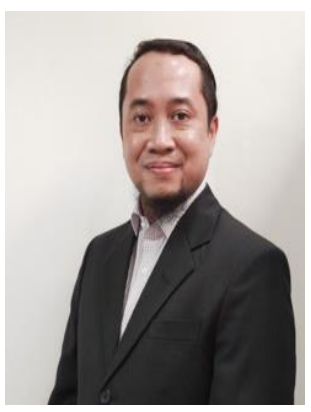

Whisnu Yudiana, M.Psi., (D) 8d SC P is a psychologist and psychometrician who currently works as a lecturer and researcher at the Department of Experimental Psychology, Faculty of Psychology Universitas Padjadjaran, Indonesia. His expertise and research focus on test development, classical and modern test theories, item response theory, Rasch's model analysis, educational psychology, human performance and ability test. He can be contacted at email: whisnu.yudiana@unpad.ac.id. 


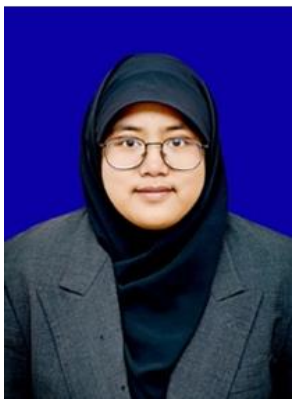

Arina Shabrina (iD $\mathrm{SCC}$ P is a researcher at the Center for Health and Wellbeing Study at the Faculty of Psychology, Universitas Padjadjaran, Indonesia. Her research focuses on health psychology, health seeking behavior, social psychology, psychosocial aspects of health behavior, and mental health. She can be contacted at email: arinashabrina@outlook.com.

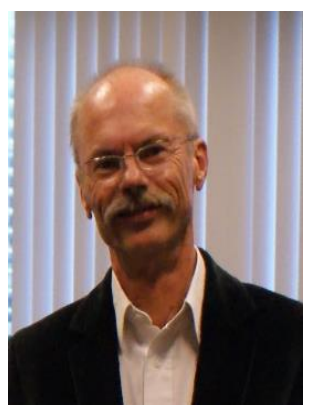

Prof. Dr. Jan Passchier (D) SC 81 P is a Professor Emeritus at the Faculty of Behavioural and Movement Sciences, Clinical Psychology, VU University Amsterdam, the Netherlands. His research focuses on psychological aspects of pain, in particular migraine and tension headache, both in children and adults. Current research in this area concerns quality of life issues in relation to cultural differences, in particular regarding Indonesia. He is chairman of the QOLMARI group, consisting of Indonesian and Dutch scientists in the area of quality of life measures and its application and able to read, speak and write Bahasa Indonesia. He can be contacted at email: j.passchier@vu.nl. 